\title{
Analysis of Synthetic Monodisperse Polysaccharides by Wide Mass Range Ultrahigh-Resolution MALDI Mass Spectrometry
}

\author{
Simone Nicolardi,* A. Abragam Joseph, Qian Zhu, Zhengnan Shen, Alonso Pardo-Vargas, \\ Fabrizio Chiodo, Antonio Molinaro, Alba Silipo, Yuri E. M. van der Burgt, Biao Yu, Peter H. Seeberger, \\ and Manfred Wuhrer
}

Cite This: Anal. Chem. 2021, 93, 4666-4675

Read Online

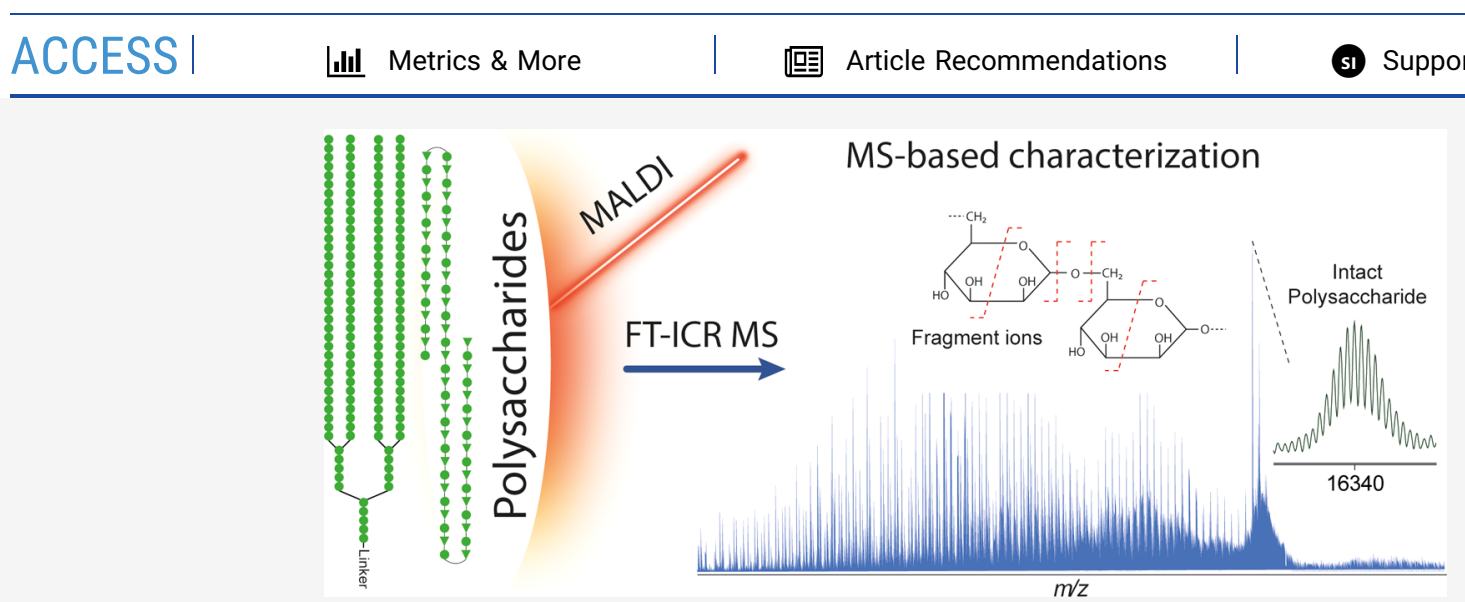

ABSTRACT: Carbohydrates, such as oligo- and polysaccharides, are highly abundant biopolymers that are involved in numerous processes. The study of their structure and functions is commonly based on a material that is isolated from complex natural sources. However, a more precise analysis requires pure compounds with well-defined structures that can be obtained from chemical or enzymatic syntheses. Novel synthetic strategies have increased the accessibility of larger monodisperse polysaccharides, posing a challenge to the analytical methods used for their molecular characterization. Here, we present wide mass range ultrahigh-resolution matrix-assisted laser desorption/ionization (MALDI) Fourier transform ion cyclotron resonance (FT-ICR) mass spectrometry (MS) as a powerful platform for the analysis of synthetic oligo- and polysaccharides. Synthetic carbohydrates 16-, 64-, 100-, and 151-mers were mass analyzed and characterized by MALDI in-source decay FT-ICR MS. Detection of fragment ions generated from glycosidic bond cleavage (or cross-ring cleavage) provided information of the monosaccharide content and the linkage type, allowing for the corroboration of the carbohydrate compositions and structures.

\section{INTRODUCTION}

Carbohydrates are a highly abundant, structurally very diverse group of molecules that contribute to the biology of living organisms in many ways. ${ }^{1}$ The structure of these biomolecules is complex as a result of monosaccharide diversity and the ways these are linked. ${ }^{2}$ Typically, oligosaccharides contain 2-20 monosaccharides, whereas larger structures are referred to as polysaccharides. $^{3}$

Studying the biological roles of carbohydrates requires compounds with well-defined chemical structures. ${ }^{4,5}$ The purification of a specific carbohydrate from a complex biological mixture can be hampered by the presence of compounds with similar physical/chemical properties that are difficult to separate. ${ }^{6,7}$ To this end, chemical, enzymatic, or chemoenzymatic syntheses are powerful alternatives to obtain highly pure compounds with tailored chemical structures while requiring control over stereo- and regiochemistry. ${ }^{8-14}$ Nevertheless, the synthesis of a large carbohydrate is challenging, and novel strategies have been developed to prepare longer polysaccharides. Recently, the syntheses of the largest monodisperse polysaccharides ever chemically prepared were reported. Automated glycan assembly was employed to prepare a branched 151-mer polymannoside with D-mannose residues connected in an $\alpha(1-6)$ linkage and an additional $\alpha 1-2$ linkage at the branching residue. ${ }^{15}$ Repeated block couplings yielded a linear 128-mer polysaccharide containing a [-4-LRha $\alpha 1-3-\mathrm{D}-\mathrm{Man} \beta 1-]$ repeating unit. ${ }^{16}$

Structure analysis of oligo- and polysaccharides is commonly performed using NMR spectroscopy and complemented by

Received: January 18, 2021

Accepted: February 19, 2021

Published: March 5, 2021 


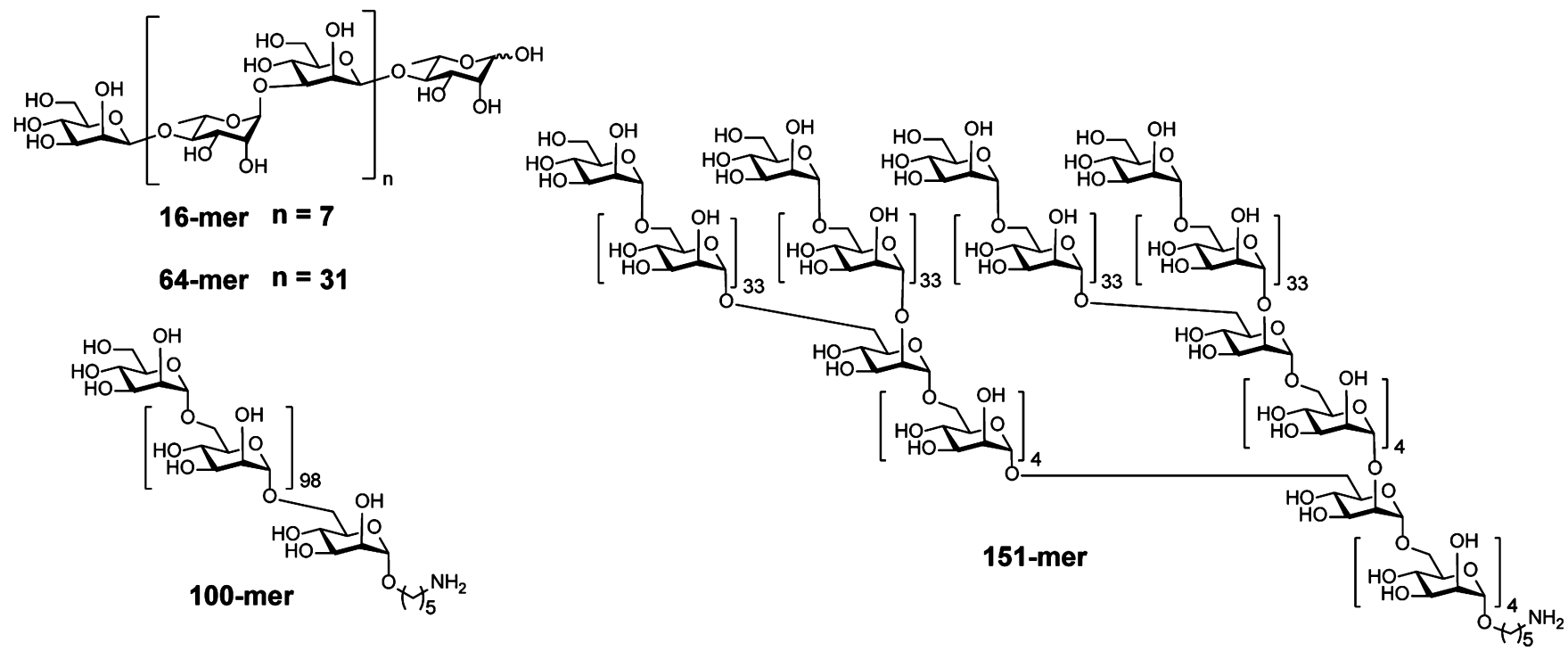

Figure 1. Chemical structures of the analyzed oligo- and polysaccharides. 16-mer and 64-mer contain a [-4-L-Rha $\alpha 1$-3-D-Man $\beta 1$-] repeating unit, while 100-mer and 151-mer were polymannosides with mannose residues connected via an $\alpha 1-6$ linkage and an additional $\alpha 1-2$ linkage at the branching residue.

other analytical techniques such as mass spectrometry (MS) that are particularly useful for the analysis of complex mixtures of carbohydrates at a low concentration. ${ }^{17-22}$ Various MSbased strategies are used to generate carbohydrate fragment ions that are informative of the monosaccharide content (such as hexoses, deoxy-hexoses, pentoses, and uronic acids) and the type of glycosidic linkages. ${ }^{23-27}$ Other characterization methods include the chemical or enzymatic treatment of carbohydrates. $^{18,19,28,29}$

The combination of matrix-assisted laser desorption/ ionization (MALDI) and time-of-flight (TOF) MS has been widely applied for oligo- and polysaccharide analysis. The resulting vast literature on MALDI-TOF MS applications is overviewed by Harvey. ${ }^{18,19}$ In MALDI TOF MS, carbohydrates can be fragmented using "post-source" or "in-source" decay (ISD) processes that are induced by a high laser fluence and/or the use of specific MALDI matrices. ${ }^{30-33}$ These processes can be combined with collision-induced dissociation for a more in-depth structural characterization. ${ }^{34}$

MALDI TOF MS is fast and allows for the analysis of carbohydrates over a wide range of masses. ${ }^{35-38}$ It provides sufficient resolving power and sensitivity for the analysis of oligosaccharides and small polysaccharides but is of limited use for the structural elucidation of larger structures since large ions are typically detected as broad peaks and overlap between signals is common. Measurements at low mass resolution can be used to determine the average mass of compounds, while measurements at isotopic resolution allow for the determination of the monoisotopic mass and provide information on the isotopic distribution. ${ }^{39}$ Deviations from the theoretical isotopic distribution may be indicative of deviations in the elemental composition or the presence of overlapping ion species. $^{40}$

Fourier transform ion cyclotron resonance (FT-ICR) MS provides higher resolving power than TOF MS. ${ }^{41}$ FT-ICR MS measurements of cesium iodide clusters $\left[\mathrm{Cs}(\mathrm{CsI})_{n}\right]^{+}$, up to about $m / z$ 32,000, have been previously reported. ${ }^{42,43}$ Ultrahigh-resolution MALDI FT-ICR MS has been used to analyze biomolecules at an isotopic resolution up to about $\mathrm{m} / \mathrm{z}$
$24,000^{44-47}$ and characterize complex biomolecules such as monoclonal antibodies. ${ }^{48-50}$ Compared to MALDI TOF MS, MALDI FT-ICR MS analysis improves the quality of the spectra with regard to a higher number of detected ion species at higher sensitivity, increased mass accuracy, and mass measurement precision. ${ }^{45,51,52}$ These characteristics have enabled the comprehensive analysis of carbohydrates, typically up to about $m / z 4000$. $^{53-59}$

Here, we demonstrate the utility of ultrahigh-resolution MALDI-ISD FT-ICR MS for the structural characterization of chemically synthesized oligo- and monodisperse polysaccharides. Synthetic carbohydrates 16-, 64-, 100-, and 151-mers (Figure 1) were mass analyzed and fragmented by ISD. The fragmentation profiles, obtained over an extended $m / z$-range, were then evaluated in detail. The measurement of both intact carbohydrates and fragment ions at resolving power and high mass accuracy allowed for the in-depth characterization of the analyzed synthetic compounds.

\section{EXPERIMENTAL SECTION}

Synthesis of 16-mer Oligosaccharide and 64-, 100-, and 151-mer Polysaccharides. The syntheses of the 16-mer oligosaccharide and the 64-, 100-, and 151-polysaccharides were recently reported. ${ }^{15,16} \mathrm{~A}$ brief description of the repeated block couplings strategy used for the synthesis of the 16-mer and 64-mer and the automated glycan assembly strategy used for the 100-mer and 151-mer is reported in the Supporting Information (Schemes $\mathrm{S} 1-\mathrm{S} 3$ ).

MALDI Spotting. The dry droplet spotting method was used in combination with a ground steel MALDI target plate (Bruker Daltonics) and "super-2,5-dihydroxybenzoic acid (DHB)" [a 9:1 (w/w) mixture of DHB and 2-hydroxy-5methoxybenzoic acid; purchased from Sigma-Aldrich] as a MALDI matrix. One microliter of each carbohydrate solution (16-mer, $1.25 \mathrm{mg} / \mathrm{mL}$; 64-mer, $1.25 \mathrm{mg} / \mathrm{mL} ; 100$ - and 151 mer, $1 \mathrm{mg} / \mathrm{mL}$; and dextran (molecular weight of about 25,000 $\mathrm{Da}), 1.8 \mathrm{mg} / \mathrm{mL}$; purchased from Sigma-Aldrich) was spotted on the target plate with either 1 or $2 \mu \mathrm{L}$ of super-DHB solution at either 5,10 , or $100 \mathrm{mg} / \mathrm{mL}$ in $50 \%$ acetonitrile. Additionally, 

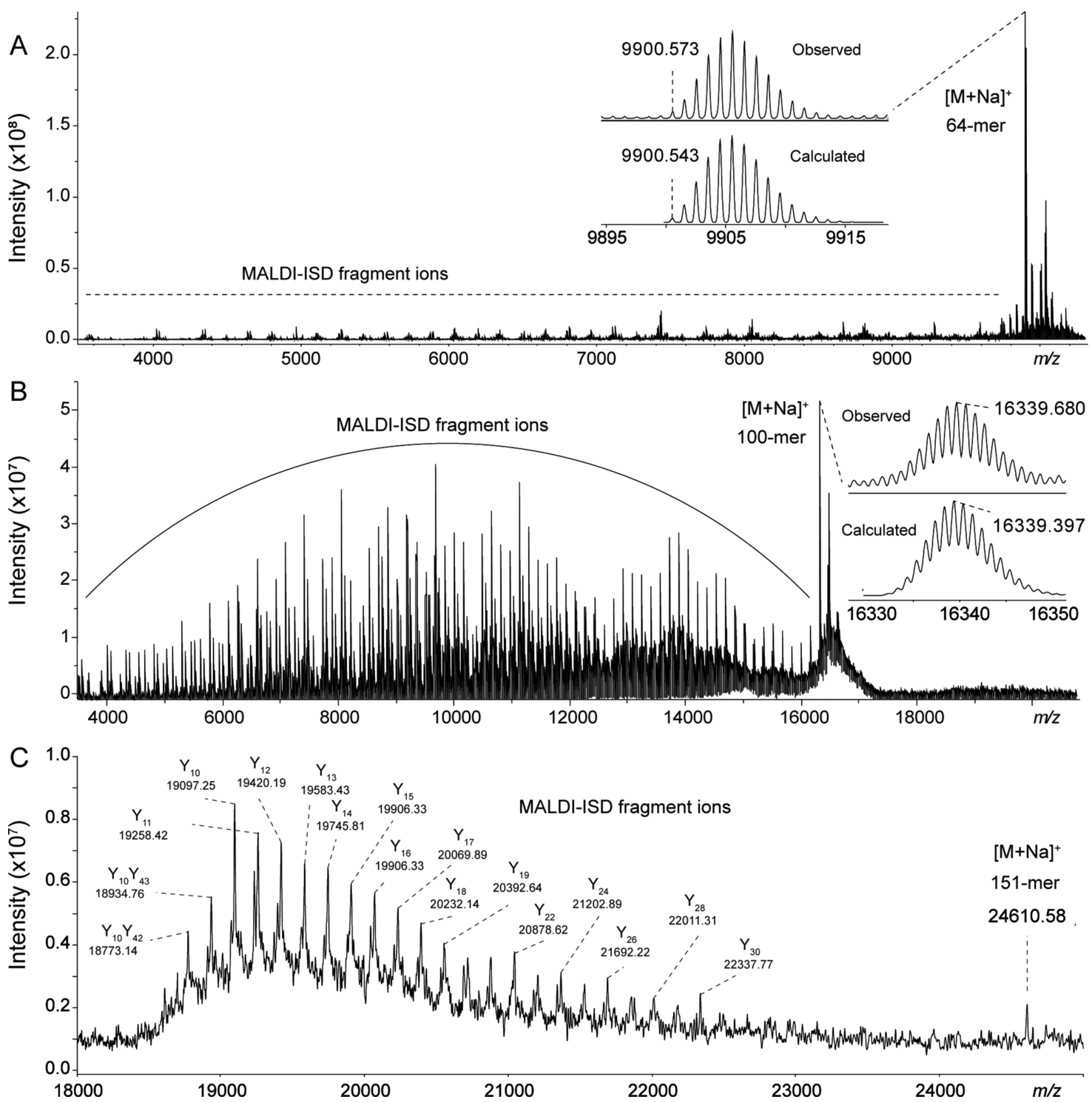

Figure 2. MALDI-(ISD) FT-ICR mass spectra of (A) 64-mer, (B) 100-mer, and (C) 151-mer polysaccharides.

for some of the spots, more super-DHB (up to $4 \mu \mathrm{L}$ ) was added to the already dried spots.

ESI and MALDI Mass Spectrometry. All MS experiments were performed on a $15 \mathrm{~T}$ solariX XR FT-ICR mass spectrometer (Bruker Daltonics) equipped with a CombiSource and a ParaCell. The MS system was operated using FTMSControl software (Bruker Daltonics). ESI MS measurements were performed by direct infusion at a flow rate of $2 \mu \mathrm{L} /$ min with a capillary voltage of $4500 \mathrm{~V}$. Collision-induced dissociation (CID) measurements were performed using the quadrupole for precursor ion selection, with an isolation window of $5 \mathrm{Th}$ and a collision energy of $55 \mathrm{~V}$. The ESI-CID mass spectrum of 16-mer was generated from the sum of 200 scans in the $m / z$-range $207-5000$ with $1 \mathrm{M}$ data points. MALDI measurements were performed using a smartbeam-II laser system (Bruker Daltonics) at a frequency of $500 \mathrm{~Hz}$ and 200 laser shots per scan. The MALDI-ISD mass spectra were acquired in the $m / z$-ranges $300-5000$ and $1000-7000$ with 1 $\mathrm{M}$ data points and the laser power at $20 \%$, and in the range 3500-30,000 with $512 \mathrm{~K}$ data points and the laser power at $25 \%$. The MALDI-ISD mass spectra were obtained from the sum of a different number of scans. The scan number ranged from $20(64$-mer; $m / z$-range $1000-7000)$ to 697 (151-mer; $m / z$-range 3500-30,000).

Data Processing. ESI and MALDI FT-ICR mass spectra were visualized in DataAnalysis version 5.0 SR1 (Bruker Daltonics), internally calibrated and exported as XY files. The theoretical fragment ions were generated in GlycoWorkbench. ${ }^{60,61}$ The elemental composition of theoretical fragment ions were generated in Microsoft Excel, and theoretical isotopic distributions were obtained using the online EnviPat tool (https://www.envipat.eawag.ch/). ${ }^{62}$ The assignments were done by a visual comparison of the MALDI mass spectra and the theoretical isotopic distributions of fragment ions in mMass. ${ }^{63}$ All figures were generated in Adobe Illustrator CC 2018. For 151-mer, a sum spectrum was generated in mMass following the workflow depicted in Figure S18.

\section{RESULTS AND DISCUSSION}

Determination of the Intact Mass of Synthetic Oligoand Monodisperse Polysaccharides by MALDI FT-ICR MS. Recently, we reported on the analysis of a linear 128-mer polysaccharide by MALDI FT-ICR MS. ${ }^{16}$ The polysaccharide 

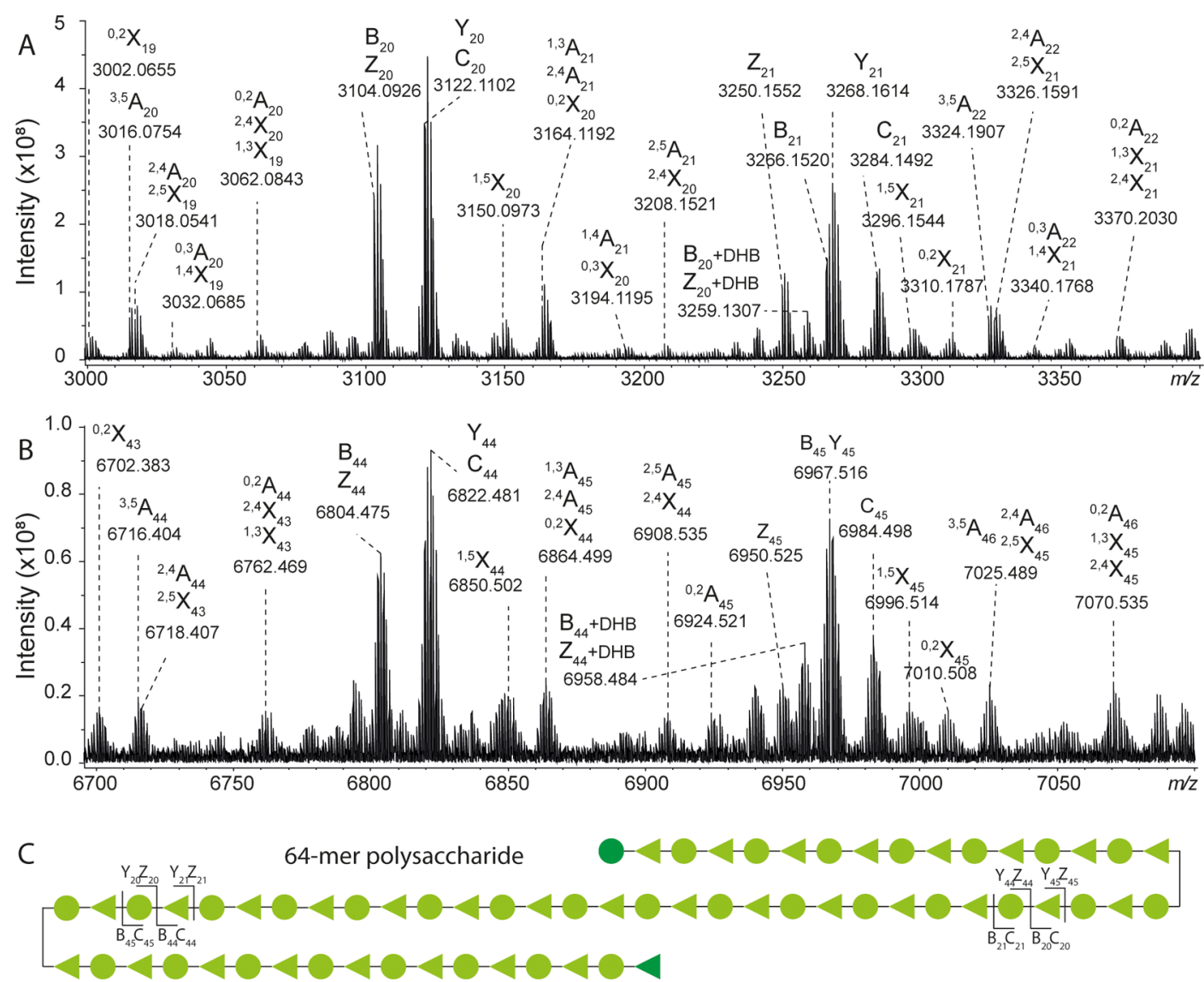

Figure 3. Enlargements of MALDI-ISD FT-ICR mass spectra of the 64-mer polysaccharide. Fragment ions were detected in clusters, as exemplified for the $m / z$-ranges $3000-3400$ (A) and 6700-7100 (B) (see also Figure S8). The labels of isomeric fragment ions are vertically aligned. (C) Schematic structure of the 64-mer polysaccharide with assigned B, C, Y, and Z fragment ions. Structural characterization of a linear 100-mer polysaccharide.

was detected at $m / z 19,769$, as a broad peak, in a lowresolution spectrum. In FT-ICR MS, the mass resolving power and the ion transmission from the ion source to the ICR cell, in commercially available instruments, vary inversely with $\mathrm{m} / \mathrm{z}$ (Supporting Information, Figures S1 and S2). Consequently, the isotopically resolved analysis of ions larger than $m / z 16,000$ is challenging. So far, MALDI FT-ICR MS has been used to analyze carbohydrates up to about $m / z 4000$, while larger molecules such as polysaccharides have been typically analyzed by low-resolution MALDI TOF MS. Here, we analyzed different synthetic monodisperse polysaccharides by MALDI FT-ICR MS to determine their intact mass. The mass spectra of 64-, 100-, and 151-mer polysaccharides are reported. These were detected as $[\mathrm{M}+\mathrm{Na}]^{+}$ions at a resolving power of about 42,500, 22,000, and 1400, respectively (Figures 2 and S3). Baseline isotopic resolution was obtained for the 64-mer with the detection of its monoisotopic peak at $\mathrm{m} / z$ 9900.573. The observed isotopic distribution of the 100-mer was in good agreement with the theoretical values; however, at such high $\mathrm{m} / z$-values, the monoisotopic peak (i.e., theoretical $\mathrm{m} / z$ $16,331.371$ ) is hardly visible, and the most abundant isotopic peak (i.e., theoretical $m / z 16,339.397$ ) was reported for this polysaccharide. For the 151-mer, mass measurement at high $\mathrm{m} / z$-values resulted in the detection of a broad peak at $\mathrm{m} / z$ $24,610.58$.

Additional adducts, at a lower intensity, were detected for 64-mer and 100-mer (Figure S3). The most intense adduct species of the 64-mer was identified as a DHB (used as a matrix) adduct ion (Figure S3A). DHB can bind to the intact polysaccharides or their fragment ions, and DHB adducts were likewise detected in the spectrum of the 100-mer (Figure S3B). In the latter spectrum, a 101-mer and 102-mer polysaccharide were detected as minor species. Other even larger species were detected in the spectra of 64 - and 100-mer at very minor amounts, but their nature was not further investigated.

The mass spectra of 64-, 100-, and 151-mer were characterized by the presence of ISD fragment ions. These provided structural information useful for the corroboration of the monosaccharide composition and linkage types.

Structural Characterization of a 16-mer Oligosaccharide. The structural characterization of carbohydrates by MS-based fragmentation techniques has been widely performed with standardized nomenclature of the fragment ions. ${ }^{64}$ The different fragmentation mechanisms can provide complementary structural information. Here, we analyzed a 16-mer oligosaccharide with a [-4Rha $\alpha 1-3 \mathrm{Man} \beta 1-]$ repeating unit by MALDI-ISD, CID FT-ICR, and ESI-CID MS (Figures S4S6). In the MALDI-ISD mass spectrum, the intact 16-mer oligosaccharide was detected as $[\mathrm{M}+\mathrm{Na}]^{+}$at $\mathrm{m} / z 2505.8848$ (theoretical $\mathrm{m} / \mathrm{z}$ 2505.8856). The most abundant fragment ions are $\mathrm{B}, \mathrm{C}, \mathrm{Y}$, and $\mathrm{Z}$ ions generated from the cleavage of a glycosidic bond. The first two types include the non-reducing end of the carbohydrate, while the other two types include the reducing end. Of note is the fact that $\mathrm{C}-2 \mathrm{H}$ (or isobaric $\mathrm{Y}-2 \mathrm{H}$ ) ions were detected for both Rha and Man residues (Figure S7). The formation of these fragment ions may involve the 

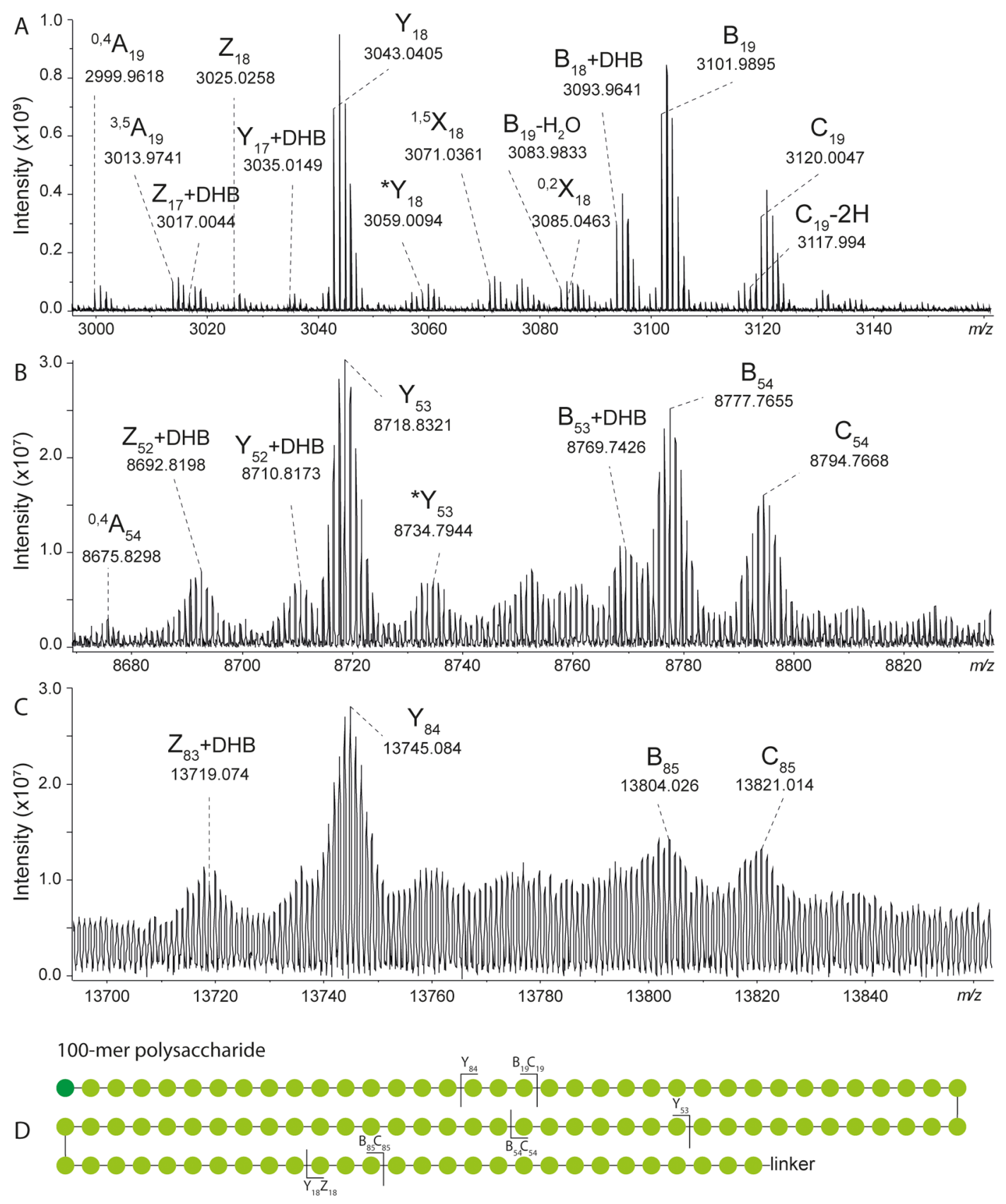

Figure 4. Enlargements of MALDI-ISD-FT ICR mass spectra of the 100-mer polymannoside shows clusters of fragment ions detected in the $m / z$ ranges 2985-3160 (A), 8670-8835 (B), and 13,695-13,862 (C). (D) Schematic structure of the 100-mer polysaccharide with assigned B, C, Y, and $\mathrm{Z}$ fragment ions. ${ }^{*}$ indicates $[\mathrm{M}+\mathrm{K}]^{+}$species.

abstraction of hydrogen atoms via a radical-based mechanism and, as previously shown for ISD fragment ions of proteins, these interfering fragments can lead to distortions of the isotopic distributions of adjacent fragment ions affecting the interpretation of the spectrum. ${ }^{65}$

When compared to ESI-CID MS, ISD analysis of the 16-mer oligosaccharide provided additional fragment ions, namely ${ }^{1,5} \mathrm{X}$, ${ }^{0,2} \mathrm{X},{ }^{3,5} \mathrm{~A}$, and $\mathrm{C}$ (Figures S4 and S6). Of note, some of the cross-ring fragments showed unique $\mathrm{m} / \mathrm{z}$-values (i.e., not isobaric with other fragment ions) that provided useful information for the corroboration of the linkage types. For example, fragment ${ }^{3,5} \mathrm{~A}_{10}$ corroborates the linkage at position 4 of the $\mathrm{Rha}_{7}$ residue, while the observation of ${ }^{0,2} \mathrm{X}_{9}$ allowed us to exclude a linkage at position 2 of $\operatorname{Man}_{10}$. The observation of cross-ring fragments makes the ISD analysis particularly valuable and complementary to ESI-CID MS for the characterization of carbohydrates. MALDI-ISD FT-ICR MS has previously been explored for protein characterization, where it likewise showed vast complementarity to other fragmentation techniques. $48,49,66$

The evaluation of the ISD mass spectra of the 16-mer oligosaccharide was facilitated by the high sensitivity and resolving power (i.e., $\sim 105,000$ at $\mathrm{m} / z 2505.8856$ ) in the analyzed $\mathrm{m} / z$ range. The analysis of the polysaccharides also benefitted from the high quality of the spectra at low $\mathrm{m} / z$ values, allowing for a reliable evaluation of the high $\mathrm{m} / z$ regions with decreased mass resolution. The mass measurement errors were in the sub- and low-ppm range. 
Intact 151-mer

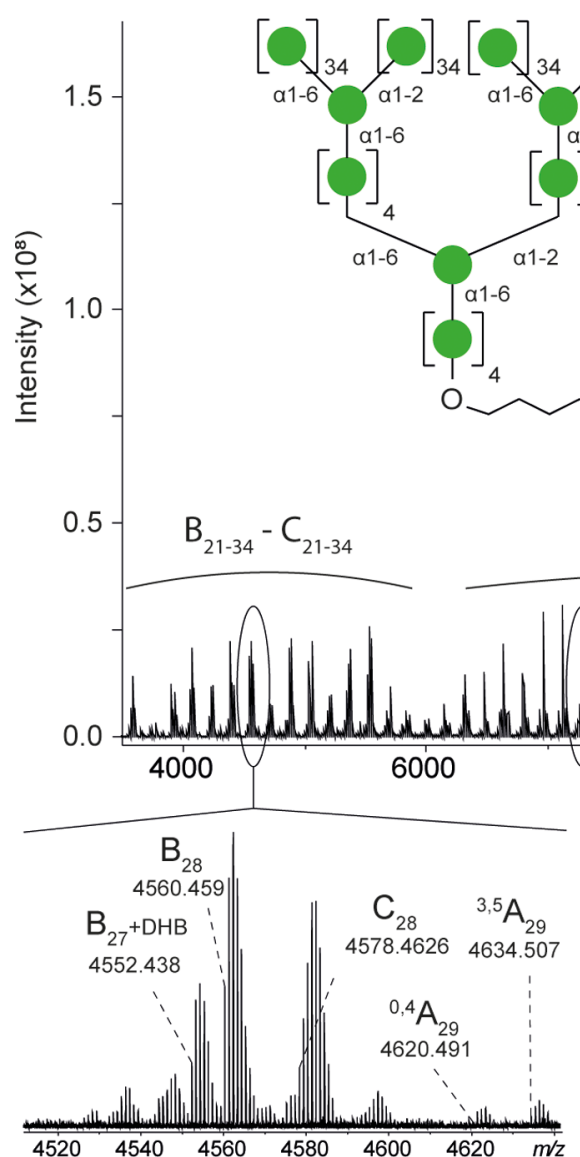

${ }^{0,2} \mathbf{X}_{4} \mathbf{Y}_{39}$ Theor. $m / z 11841.92$

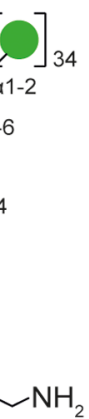

$B Y-Y C-Y Y-0,2 X Y$

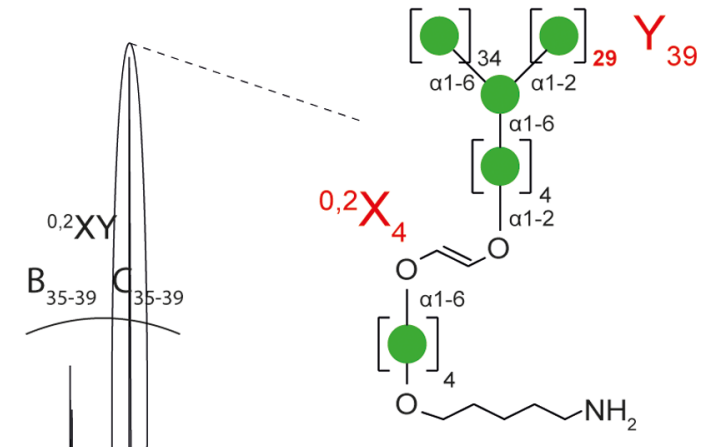

$Y_{6-31}$

Figure 5. MALDI-ISD FT-ICR mass spectrum of 151-mer in the $m / z$-range $3500-17,000$. Intense fragment ions were generated from a double cleavage: one ${ }^{0,2} \mathrm{X}$ cross-ring fragmentation at the branching residue Man5 and one $\mathrm{Y}$ fragmentation.

In general, many isomeric fragment ions can be obtained from a carbohydrate structure, such that the interpretation of a fragmentation spectrum may not be trivial. Large monodisperse polysaccharides, like those presented here, have never been characterized by ultrahigh-resolution MALDI-ISD FTICR MS over an extended $m / z$-range. This is due to the uniqueness of both the analyzed compounds and the used MS methods.

Structural Characterization of a Linear 64-mer Polysaccharide. The linear 64-mer polysaccharide shares the [-4Rha $\alpha 1-3 \mathrm{Man} \beta 1-]$ disaccharide repeating unit with the 16-mer. Due to the repeating nature of the structure of this monodisperse polysaccharide, the ISD fragment ions were detected in clusters (Figure S8). These clusters showed $\mathrm{m} / z$ differences of about 308 (theoretical $\Delta m / z=308.1107$ ), corresponding to the sum of one mannose and one rhamnose residue. Two representative fragment ion clusters detected at different $\mathrm{m} / \mathrm{z}$-ranges in the mass spectra of the 64-mer are depicted in Figure 3. The most intense fragment ions were generated from the cleavage of the glycosidic bonds, while cross-ring fragments were detected at lower intensities. Many of the fragment ions are isomeric and could not be distinguished (e.g., ${ }^{1,3} \mathrm{~A}_{21},{ }^{2,4} \mathrm{~A}_{21}$, and ${ }^{0,2} \mathrm{X}_{20}$ ). Unique fragments were $B$ and $C$ ions (e.g., $B_{43}$ and $C_{43}$ ) that generated at the Man residue side and $\mathrm{Y}$ and $\mathrm{Z}$ ions (e.g., $\mathrm{Y}_{21}$ and $\mathrm{Z}_{21}$ ) that generated at the Rha residue side. Hydrogen abstraction and losses of neutrals (e.g., $\mathrm{H}_{2} \mathrm{O}$ ) during the ISD process led to interfering species (Figure S9). The reliable identification of these species at low $m / z$-values explains the distortions observed at higher $m / z$-values. Other fragments with unique $m / z$-values are ${ }^{1,5} \mathrm{X}$ and ${ }^{3,5} \mathrm{~A}$ ions (e.g., ${ }^{1,5} \mathrm{X}_{20}$ and ${ }^{3,5} \mathrm{~A}_{44}$ ) that are generated at $\mathrm{Rha}$ residues and ${ }^{1,5} \mathrm{X}$ and ${ }^{0,2} \mathrm{X}$ ions that are generated at Man residues (e.g., ${ }^{1,5} X_{21}$ and ${ }^{0,2} X_{19}$ ). Of these, for example, ${ }^{3,5} \mathrm{~A}$ ions corroborate the linkage at position 4 . With the increasing fragment ion size, the isotopic distributions become larger, and the overlaps between adjacent distributions in the spectra increase (Figure S10), thus complicating the interpretation of the spectra. Small fragment ions were also detected in the $m / z$ region $(m / z<1000)$ that is dominated by the MALDI matrix ions (Figure S11). The high-resolution measurements allowed for the confident assignment of fragment ions in this crowded region. Thus, the analysis of MALDI-ISD fragment ions in the $\mathrm{m} / \mathrm{z}$-range $300-9920$ led to the characterization of 61 out of 63 glycosidic bonds corresponding to $97 \%$ carbohydrate sequence coverage.

The analyzed linear 100-mer $\alpha$ 1-6 polymannoside contains a five-carbon aliphatic linker, with a terminal primary amine bound to the reducing end. The linker provided a mass tag of 85.0891 Da, allowing us to differentiate $\mathrm{X}, \mathrm{Y}$, and $\mathrm{Z}$ fragments, which included the terminal linker, from $\mathrm{A}, \mathrm{B}$, and $\mathrm{C}$ ions (e.g., $\mathrm{Y}_{18}$ at $\mathrm{m} / z 3044.0432$ and $\mathrm{C}_{18}$ at $\left.m / z 2958.9540\right)$. Similar to the 64-mer polysaccharide described above, the fragmentation of the linear 100-mer polymannoside also resulted in the detection of clusters of fragment ions (Figure S12). The $\mathrm{m} / z$ 
difference between clusters, corresponding to one Man residue, was about 162 (theoretical $\Delta m / z=162.0528$ ). Three examples of ISD fragment ion clusters, detected in different $m / z$-ranges, are reported in Figure 4. As shown for the 64-mer polysaccharide, with the increasing fragment ion size, the quality of the isotopic distributions decreases due to a lower signal-to-noise ratio $(\mathrm{S} / \mathrm{N})$, complicating the interpretation of the spectra.

Within each cluster, the most abundant fragment ions were $\mathrm{B}, \mathrm{B}+\mathrm{DHB}, \mathrm{C}$, and $\mathrm{Y}$, while cross-ring fragments and other DHB adducts were detected at lower intensities. The detection of ${ }^{0,4} \mathrm{~A},{ }^{3,5} \mathrm{~A}$, and ${ }^{1,5} \mathrm{X}$ cross-ring fragments corroborated the $1-$ 6 linkage between mannose residues. ${ }^{0,2} \mathrm{X}$ fragment ions were also detected but at a lower intensity. The identification of this type of fragment was hampered by the partial overlap with B$\mathrm{H}_{2} \mathrm{O}$ fragments (Figure S13). ${ }^{0,2} \mathrm{X}$ fragmentation of oligosaccharides with $\alpha 1-6$ linked hexose residues was previously reported. For example, Bashir and co-workers analyzed linear dextran oligomers, with an $\alpha 1-6$ linkage, using MALDI-ISD, -PSD, and -CID MS and identified ${ }^{0,2} \mathrm{X}$ fragment ions in all three different fragmentation spectra. ${ }^{67}$ Similarly, we identified ${ }^{0,2} \mathrm{X}$ fragment ions of dextran, a polyglucoside with $\alpha 1-6$ linkages with an average mass of about 25,000 Da, in MALDIISD FT-ICR mass spectra (Figure S14). Additionally, ${ }^{0,2} \mathrm{X}$ fragmentation was reported for other oligosaccharides, linkage types, and fragmentation techniques. ${ }^{23,25,26,53,68-73}$

In general, due to the higher resolving power and the narrower isotopic distributions at low $\mathrm{m} / z$-values, more fragment ions can be identified accurately in the low $m / z$ region. At higher $m / z$-values, the overlap between adjacent isotopic distributions increased as a consequence of the lower resolving power and the broader distributions. Finally, based on the detection of $\mathrm{Y}$ ions, from $\mathrm{Y}_{3}$ until $\mathrm{Y}_{99}$, a sequence coverage of $98 \%$ was obtained.

Structural Characterization of a Branched 151-mer Polysaccharide. The synthetic branched 151-mer polymannoside also contains an aliphatic linker at the reducing end. The mannose residues are $\alpha 1-6$ linked, with an additional $\alpha 1-2$ linkage at the branching residue. In the MALDI-ISD FTICR mass spectrum of 151 -mer, in the $\mathrm{m} / \mathrm{z}$-range $18,000-$ 25,000 , intense $\mathrm{Y}$ type fragment ions were detected (Figure $2 \mathrm{C})$. The ISD mass spectrum of the 151 -mer, in the $m / z$-range $3500-17,000$, is depicted in Figure 5. The branched nature of the compound was taken into account for the assignment of these fragments (Figure S15). The ion species were identified as fragment ions that were generated from the cleavage of either one or two glycosidic bonds (Figure S16). For example, two fragment ions were detected at $\mathrm{m} / z 5694.8466$ and $\mathrm{m} / z$ 5712.8507 , respectively (Figure S17). These correspond to $\mathrm{B}$ and $C$ ions with 35 mannose residues. However, $B_{35}$ and $C_{35}$ generate from the cleavage of the glycosidic bond at the reducing end side of the branching mannose residue, producing ions of 69 (i.e. $34+34+1$ ) mannose residues, with $\mathrm{m} / z \quad 11,209.950$ and $\mathrm{m} / z \quad 11,227.660$, respectively (Figures S15 and S16). Furthermore, theoretical $\mathrm{Y}_{4}$ has $\mathrm{m} / z$ 774.300, while $\mathrm{Y}_{5}$ (with 78 mannose residues) has $\mathrm{m} / \mathrm{z}$ 12,772.228; therefore, a double glycosidic bond cleavage was hypothesized to explain the fragment ions detected in the $\mathrm{m} / \mathrm{z}$ region 5715-12,772, and the two fragment ions detected at $m / z 5694.8466$ and $m / z 5712.8507$ were identified as $\mathrm{B}_{35} \mathrm{Y}_{10}$ and $\mathrm{C}_{35} \mathrm{Y}_{10}$, respectively.

In the spectrum, BY, CY, YY, ZY, and $\mathrm{YZ}+\mathrm{DHB}$ ions were identified as major species. In addition to these fragment ions, a series of intense ${ }^{0,2} \mathrm{XY}$ ions was detected. The data suggest that the ${ }^{0,2} \mathrm{X}$ fragmentation at the branching residue, with an $\alpha 1-2$ linkage, is preferred over other cross-ring fragmentation types and that the combination with $\mathrm{Y}$ fragmentation leads to the intense fragment ions. In fact, the most intense fragment ions in the spectrum, detected in the $m / z$-range 6000-12,000, were also of this type. ${ }^{0,2} \mathrm{X}$ fragment ions generated at mannose residues with $\alpha 1-6$ linkages were not detected probably due to their low abundance and possible overlap with $\mathrm{B}-\mathrm{H}_{2} \mathrm{O}$ fragment ions (see Figure S13). ${ }^{0,2} \mathrm{X}$ fragmentation at monosaccharide residues connected via an $\alpha 1-2$ linkage was previously reported. ${ }^{53,70}$ For example, Park and Lebrilla analyzed lacto- $N$-fucopentaose-I by MALDI-CID MS and identified a ${ }^{0,2} \mathrm{X}$ fragment ion diagnostic for the $\alpha 1-2$ linkage between a fucose and a galactose residue (i.e., Fuc $\alpha 1-2 \mathrm{Man}){ }^{53}$

Finally, interpretation of the ISD mass spectra of 151-mer was facilitated by comparison with the mass spectra obtained from the linear 100-mer polysaccharide (Figure S18).

Of note, the analysis of large polydisperse polysaccharides by MALDI MS is not trivial and has often required fractionation of the carbohydrate mixture before MS measurements. ${ }^{74,75}$ The here reported detection of large monodisperse polysaccharides and their ISD fragments by MALDI FT-ICR MS brings new insights into the ionizability of such large carbohydrates and warrants further research on naturally occurring polydisperse polysaccharides.

\section{CONCLUSIONS}

Recent developments in carbohydrate synthesis provide access to large synthetic polysaccharides. These precisely defined structures are required to understand the structure and function of carbohydrates and are of interest for future biomaterial and biomedical science applications. Notably, their size and complexity are a challenge for analytical methods; thus, novel strategies are needed to analyze and ascertain the correct carbohydrate composition and purity.

Mass spectrometry has been extensively used for the characterization of carbohydrates, albeit high-resolution measurements have only been performed on oligosaccharides. So far, polysaccharides have been analyzed at lower resolution (i.e., broad peak). Here, we reported the analysis of different synthetic oligo- and monodisperse polysaccharides by wide $m$ / $z$ range ultrahigh-resolution MALDI FT-ICR MS. Here, we analyzed different synthetic oligo- and polysaccharides by wide $m / z$ range ultrahigh-resolution MALDI FT-ICR MS. Measurements at the isotopic resolution allowed for an accurate determination of the mass of the intact polysaccharides up to $\mathrm{m} / z 16,000$ by distinguishing these compounds from other less abundant ion species. FT-ICR MS measurements at lower resolution enabled the detection of the largest ever synthesized polysaccharide-a 151-mer polymannoside-at higher $\mathrm{m} /$ zvalues (approximately $\mathrm{m} / z$ 24,600). Furthermore, oligo- and polysaccharides were sequenced by MALDI-ISD FT-ICR MS over an extended $\mathrm{m} / z$-range. The ultrahigh resolution measurements enabled an in-depth interpretation of the spectra that included structural information on both carbohydrate composition and linkage types of linear as well as branched polysaccharides. It was shown that ultrahighresolution MALDI-(ISD) FT-ICR MS is a powerful analytical tool for the analysis of synthetic oligo- and polysaccharides that contributes to a more comprehensive structural characterization of large, synthetic, and monodisperse carbohydrates. Compared to other MALDI MS platforms (e.g., MALDI 
Orbitrap MS), the developed method allows for mass measurements of polysaccharides at a higher resolving power in a larger $\mathrm{m} / \mathrm{z}$-range. We envision broader applicability of this analytical approach with applications ranging from the biopharma (e.g., analysis of glycoconjugate vaccines and heparins) to the food industry (e.g., analysis of pectin).

\section{ASSOCIATED CONTENT}

\section{SI Supporting Information}

The Supporting Information is available free of charge at https://pubs.acs.org/doi/10.1021/acs.analchem.1c00239.

Evaluation of the mass resolution and the mass measurement precision; analysis of $\left[(\mathrm{CsI})_{n}+\mathrm{Cs}\right]^{+}$ cluster ions by MALDI FT-ICR MS; examples of CsI ion clusters; enlargement of mass spectra of 64-mer and 100-mer polysaccharides; comparison between MALDIISD, MALDI-CID, and ESI-CID FT-ICR MS; MALDIISD FT-ICR mass spectrum of 16-mer oligosaccharide; MALDI-CID FT-ICR mass spectrum of the singly sodiated 16-mer oligosaccharide; ESI-CID FT-ICR MS of the doubly sodiated 16-mer oligosaccharide; enlargements of MALDI-ISD FT-ICR mass spectra of the 16mer oligosaccharide; MALDI-ISD FT-ICR mass spectrum of the 64-mer in the $\mathrm{m} / \mathrm{z}$-range $1000-7000$; enlargement of MALDI-ISD FT-ICR mass spectra of the 64-mer polysaccharide; examples of isotopic distributions of adjacent fragment ions (i.e., ${ }^{3,5} \mathrm{~A},{ }^{2,4} \mathrm{~A}$, and ${ }^{2,5} \mathrm{X}$ ); examples of fragment ions detected in the MALDI matrix region (below $m / z$ 1000); MALDI-ISD FT-ICR mass spectrum of the 100 -mer in the $m / z$-range $1000-$ 7000; enlargement of MALDI-ISD FT-ICR mass spectrum of the 100-mer polysaccharide; MALDI-ISD FT-ICR mass spectrum of dextran; schematic structure of the 151-mer and nomenclature used for the assignment of ISD fragment ions; examples of assigned ISD fragment ions of the 151-mer polysaccharide; examples of fragment ions generating from the cleavage of two glycosidic bonds; comparison between ISD mass spectra of 151-mer and 100-mer polysaccharides; and experimental details (PDF)

\section{AUTHOR INFORMATION}

\section{Corresponding Author}

Simone Nicolardi - Center for Proteomics and Metabolomics, Leiden University Medical Center, Leiden 2333 ZA, The Netherlands; 이이.org/0000-0001-8393-1625; Email: s.nicolardi@lumc.nl

\section{Authors}

A. Abragam Joseph - Department of Biomolecular Systems, Max-Planck-Institute of Colloids and Interfaces, 14476 Potsdam, Germany; 이이.org/0000-0003-3584-0408

Qian Zhu - State Key Laboratory of Bioorganic and Natural Products Chemistry, Center for Excellence in Molecular Synthesis, Shanghai Institute of Organic Chemistry, University of Chinese Academy of Sciences, Chinese Academy of Sciences, Shanghai 200032, China

Zhengnan Shen - School of Physical Science and Technology, ShanghaiTech University, Shanghai 201210, China

Alonso Pardo-Vargas - Department of Biomolecular Systems, Max-Planck-Institute of Colloids and Interfaces, 14476
Potsdam, Germany

Fabrizio Chiodo - Institute of Biomolecular Chemistry (ICB), Italian National Research Council (CNR), Napoli 80078, Italy; Amsterdam UMC-Locatie VUMC, Molecular Cell Biology and Immunology, Amsterdam $1081 \mathrm{HZ}$, The Netherlands; 이이.org/0000-0003-3619-9982

Antonio Molinaro - Department of Chemical Sciences, University of Naples Federico II, Napoli 80126, Italy; (1) orcid.org/0000-0002-3456-7369

Alba Silipo - Department of Chemical Sciences, University of Naples Federico II, Napoli 80126, Italy; 10 orcid.org/00000002-5394-6532

Yuri E. M. van der Burgt - Center for Proteomics and Metabolomics, Leiden University Medical Center, Leiden 2333 ZA, The Netherlands; (1) orcid.org/0000-0003-05565564

Biao Yu - State Key Laboratory of Bioorganic and Natural Products Chemistry, Center for Excellence in Molecular Synthesis, Shanghai Institute of Organic Chemistry, University of Chinese Academy of Sciences, Chinese Academy of Sciences, Shanghai 200032, China; School of Chemistry and Materials Science, Hangzhou Institute for Advanced Study, University of Chinese Academy of Sciences, Hangzhou 310024, China

Peter H. Seeberger - Department of Biomolecular Systems, Max-Planck-Institute of Colloids and Interfaces, 14476 Potsdam, Germany; Institute of Chemistry and Biochemistry, Freie Universität Berlin, Berlin 14195, Germany

Manfred Wuhrer - Center for Proteomics and Metabolomics, Leiden University Medical Center, Leiden 2333 ZA, The Netherlands; ○ orcid.org/0000-0002-0814-4995

Complete contact information is available at:

https://pubs.acs.org/10.1021/acs.analchem.1c00239

\section{Notes}

The authors declare no competing financial interest.

\section{ACKNOWLEDGMENTS}

We gratefully acknowledge the generous financial support of the Max Planck Society.

\section{REFERENCES}

(1) Varki, A. Glycobiology 2017, 27, 3-49.

(2) Mariño, K.; Bones, J.; Kattla, J. J.; Rudd, P. M. Nat. Chem. Biol. 2010, 6, 713-723.

(3) Seeberger, P. H. Monosaccharide Diversity. In Essentials of Glycobiology, Varki, A.; Cummings, R. D., Esko, J. D., Stanley, P., Hart, G. W., Aebi, M., Darvill, A. G., Kinoshita, T., Packer, N. H., Prestegard, J. H., Schnaar, R. L., Seeberger, P. H., Ed.; Cold Spring Harbor Laboratory Press: Cold Spring Harbor, NY, 2015; pp 19-30.

(4) Yamada, K.; Kakehi, K. J. Pharm. Biomed. 2011, 55, 702-727.

(5) Astronomo, R. D.; Burton, D. R. Nat. Rev. Drug Discov. 2010, 9, $308-324$

(6) Zhang, Q.; Li, Z.; Song, X. Front. Chem. 2020, 8, 508.

(7) Morais, V.; Dee, V.; Suárez, N. Front. Bioeng. Biotechnol. 2018, 6, 145.

(8) Zhu, X.; Schmidt, R. R. Angew. Chem., Int. Ed. 2009, 48, 19001934.

(9) Yu, H.; Chen, X. Org. Biomol. Chem. 2016, 14, 2809-2818.

(10) Wen, L.; Edmunds, G.; Gibbons, C.; Zhang, J.; Gadi, M. R.; Zhu, H.; Fang, J.; Liu, X.; Kong, Y.; Wang, P. G. Chem. Rev. 2018, $118,8151-8187$. 
(11) Zhang, X.; Pagadala, V.; Jester, H. M.; Lim, A. M.; Pham, T. Q.; Goulas, A. M. P.; Liu, J.; Linhardt, R. J. Chem. Sci. 2017, 8, 79327940.

(12) Schumann, B.; Pragani, R.; Anish, C.; Pereira, C. L.; Seeberger,

P. H. Chem. Sci. 2014, 5, 1992-2002.

(13) Yang, Y.; Martin, C. E.; Seeberger, P. H. Chem. Sci. 2012, 3, 896-899.

(14) Calin, O.; Eller, S.; Seeberger, P. H. Angew. Chem., Int. Ed. 2013, 52, 5862-5865.

(15) Joseph, A. A.; Pardo-Vargas, A.; Seeberger, P. H. J. Am. Chem. Soc. 2020, 142, 8561-8564.

(16) Zhu, Q.; Shen, Z.; Chiodo, F.; Nicolardi, S.; Molinaro, A.; Silipo, A.; Yu, B. Nat. Commun. 2020, 11, 4142.

(17) Duus, J. Ø.; Gotfredsen, C. H.; Bock, K. Chem. Rev. 2000, 100, $4589-4614$.

(18) Harvey, D. J. Mass Spectrom. Rev. 1999, 18, 349-450.

(19) Harvey, D. J. Mass Spectrom. Rev. 2018, 37, 353-491.

(20) Obena, R. P.; Tseng, M.-C.; Primadona, I.; Hsiao, J.; Li, I.-C.; Capangpangan, R. Y.; Lu, H.-F.; Li, W.-S.; Chao, I.; Lin, C.-C.; Chen, Y.-J. Chem. Sci. 2015, 6, 4790-4800.

(21) Mucha, E.; Stuckmann, A.; Marianski, M.; Struwe, W. B.; Meijer, G.; Pagel, K. Chem. Sci. 2019, 10, 1272-1284.

(22) Mohr, M. D.; OlafBörnsen, K.; Widmer, H. M. Rapid Commun. Mass Spectrom. 1995, 9, 809-814.

(23) Han, L.; Costello, C. E. J. Am. Soc. Mass Spectrom. 2011, 22, 997-1013.

(24) Wilson, J. J.; Brodbelt, J. S. Anal. Chem. 2008, 80, 5186-5196.

(25) Desai, N.; Thomas, D. A.; Lee, J.; Gao, J.; Beauchamp, J. L. Chem. Sci. 2016, 7, 5390-5397.

(26) Liu, P.; Zhao, P.; Cooks, R. G.; Chen, H. Chem. Sci. 2017, 8, 6499-6507.

(27) O'Brien, J. P.; Needham, B. D.; Brown, D. B.; Trent, M. S.; Brodbelt, J. S. Chem. Sci. 2014, 5, 4291-4301.

(28) Rudd, P. M.; Gulle, G. R.; Küster, B.; Harvey, D. J.; Opdenakker, G.; Dwek, R. A. Nature 1997, 388, 205-207.

(29) Lamari, F. N.; Kuhn, R.; Karamanos, N. K. J. Chromatogr. B: Anal. Technol. Biomed. Life Sci. 2003, 793, 15-36.

(30) Talbo, G.; Mann, M. Rapid Commun. Mass Spectrom. 1996, 10, $100-103$.

(31) Harvey, D. J.; Hunter, A. P.; Bateman, R. H.; Brown, J.; Critchley, G. Int. J. Mass Spectrom. 1999, 188, 131-146.

(32) Smargiasso, N.; De Pauw, E. Anal. Chem. 2010, 82, 9248-9253.

(33) Asakawa, D.; Smargiasso, N.; De Pauw, E. Anal. Chem. 2012, 84, 7463-7468.

(34) Wuhrer, M.; Deelder, A. M. Rapid Commun. Mass Spectrom. 2006, 20, 943-951.

(35) Deery, M. J.; Stimson, E.; Chappell, C. G. Rapid Commun. Mass Spectrom. 2001, 15, 2273-2283.

(36) López-García, M.; García, M. S. D.; Vilariño, J. M. L.; Rodríguez, M. V. G. Food Chem. 2016, 199, 597-604.

(37) Huang, M.-F.; Chang, H.-T. Chem. Sci. 2012, 3, 2147-2152.

(38) Sanchez-Ruiz, A.; Serna, S.; Ruiz, N.; Martin-Lomas, M.; Reichardt, N.-C. Angew. Chem., Int. Ed. 2011, 50, 1801-1804.

(39) Rockwood, A. L.; Palmblad, M. Isotopic Distributions. In Mass Spectrometry Data Analysis in Proteomics; Matthiesen, R., Ed.; Humana Press: Totowa, NJ, 2013; Vol. 1007, pp 65-99.

(40) Nicolardi, S.; Palmblad, M.; Dalebout, H.; Bladergroen, M.; Tollenaar, R. A.; Deelder, A. M.; van der Burgt, Y. E. J. Am. Soc. Mass Spectrom. 2010, 21, 1515-1525.

(41) Marshall, A. G.; Hendrickson, C. L.; Jackson, G. S. Mass Spectrom. Rev. 1998, 17, 1-35.

(42) Amster, I. J.; McLafferty, F. W.; Castro, M. E.; Russell, D. H.;

Cody, R. B.; Ghaderi, S. Anal. Chem. 1986, 58, 483-485.

(43) Lebrilla, C. B.; Wang, D. T.; Hunter, R. L.; McIver, R. T. Anal. Chem. 1990, 62, 878-880.

(44) Nicolardi, S.; Switzar, L.; Deelder, A. M.; Palmblad, M.; van der Burgt, Y. E. Anal. Chem. 2015, 87, 3429-3437.
(45) Dilillo, M.; Ait-Belkacem, R.; Esteve, C.; Pellegrini, D.; Nicolardi, S.; Costa, M.; Vannini, E.; Graaf, E. L.; Caleo, M.; McDonnell, L. A. Sci. Rep. 2017, 7, 603.

(46) Prentice, B. M.; Ryan, D. J.; Van de Plas, R.; Caprioli, R. M.; Spraggins, J. M. Anal. Chem. 2018, 90, 5090-5099.

(47) Castoro, J. A.; Wilkins, C. L. Anal. Chem. 1993, 65, 2621-2627.

(48) van der Burgt, Y. E. M.; Kilgour, D. P. A.; Tsybin, Y. O.; Srzentić, K.; Fornelli, L.; Beck, A.; Wuhrer, M.; Nicolardi, S. Anal. Chem. 2019, 91, 2079-2085.

(49) Gstöttner, C.; Reusch, D.; Haberger, M.; Dragan, I.; Van Veelen, P.; Kilgour, D. P. A.; Tsybin, Y. O.; van der Burgt, Y. E. M.; Wuhrer, M.; Nicolardi, S. mAbs 2020, 12, 1682403.

(50) Tran, B. Q.; Barton, C.; Feng, J.; Sandjong, A.; Yoon, S. H.; Awasthi, S.; Liang, T.; Khan, M. M.; Kilgour, D. P.; Goodlett, D. R.; Goo, Y. A. Data Brief 2016, 6, 68-76.

(51) Spraggins, J. M.; Rizzo, D. G.; Moore, J. L.; Rose, K. L.; Hammer, N. D.; Skaar, E. P.; Caprioli, R. M. J. Am. Soc. Mass Spectrom. 2015, 26, 974-985.

(52) Fleurbaaij, F.; Kraakman, M. E.; Claas, E. C.; Knetsch, C. W.; van Leeuwen, H. C.; van der Burgt, Y. E.; Veldkamp, K. E.; Vos, M. C.; Goessens, W.; Mertens, B. J.; Kuijper, E. J.; Hensbergen, P. J.; Nicolardi, S. Anal. Chem. 2016, 88, 5996-6003.

(53) Park, Y.; Lebrilla, C. B. Mass Spectrom. Rev. 2005, 24, 232-264.

(54) Zhou, W.; Håkansson, K. Curr. Proteomics 2011, 8, 297-308.

(55) Vreeker, G. C. M.; Nicolardi, S.; Bladergroen, M. R.; van der Plas, C. J.; Mesker, W. E.; Tollenaar, R. A. E. M.; van der Burgt, Y. E. M.; Wuhrer, M. Anal. Chem. 2018, 90, 11955-11961.

(56) Zhang, J.; LaMotte, L.; Dodds, E. D.; Lebrilla, C. B. Anal. Chem. 2005, 77, 4429-4438.

(57) Mehra, R.; Barile, D.; Marotta, M.; Lebrilla, C. B.; Chu, C.; German, J. B. PLoS One 2014, 9, No. e96040.

(58) Pfenninger, A.; Chan, S. Y.; Karas, M.; Finke, B.; Stahl, B.; Costello, C. E. Int. J. Mass Spectrom. 2008, 278, 129-136.

(59) Powers, T. W.; Jones, E. E.; Betesh, L. R.; Romano, P. R.; Gao, P.; Copland, J. A.; Mehta, A. S.; Drake, R. R. Anal. Chem. 2013, 85, 9799-9806.

(60) Ceroni, A.; Maass, K.; Geyer, H.; Geyer, R.; Dell, A.; Haslam, S. M. J. Proteome Res. 2008, 7, 1650-1659.

(61) Damerell, D.; Ceroni, A.; Maass, K.; Ranzinger, R.; Dell, A.; Haslam, S. M. Biol. Chem. 2012, 393, 1357-1362.

(62) Loos, M.; Gerber, C.; Corona, F.; Hollender, J.; Singer, H. Anal. Chem. 2015, 87, 5738-5744.

(63) Strohalm, M.; Hassman, M.; Košata, B.; Kodícek, M. Rapid Commun. Mass Spectrom. 2008, 22, 905-908.

(64) Domon, B.; Costello, C. E. Glycoconj. J. 1988, 5, 397-409.

(65) Nicolardi, S.; Kilgour, D. P. A.; Dolezal, N.; Drijfhout, J. W.; Wuhrer, M.; van der Burgt, Y. E. M. Anal. Chem. 2020, 92, 58715881.

(66) Srzentić, K.; Fornelli, L.; Tsybin, Y. O.; Loo, J. A.; Seckler, H.; Agar, J. N.; Anderson, L. C.; Bai, D. L.; Beck, A.; Brodbelt, J. S.; van der Burgt, Y. E. M.; Chamot-Rooke, J.; Chatterjee, S.; Chen, Y.; Clarke, D. J.; Danis, P. O.; Diedrich, J. K.; D’Ippolito, R. A.; Dupré, M.; Gasilova, N.; Ge, Y.; Goo, Y. A.; Goodlett, D. R.; Greer, S.; Haselmann, K. F.; He, L.; Hendrickson, C. L.; Hinkle, J. D.; Holt, M. V.; Hughes, S.; Hunt, D. F.; Kelleher, N. L.; Kozhinov, A. N.; Lin, Z.; Malosse, C.; Marshall, A. G.; Menin, L.; Millikin, R. J.; Nagornov, K. O.; Nicolardi, S.; Paša-Tolić, L.; Pengelley, S.; Quebbemann, N. R.; Resemann, A.; Sandoval, W.; Sarin, R.; Schmitt, N. D.; Shabanowitz, J.; Shaw, J. B.; Shortreed, M. R.; Smith, L. M.; Sobott, F.; Suckau, D.; Toby, T.; Weisbrod, C. R.; Wildburger, N. C.; Yates, J. R.; Yoon, S. H.; Young, N. L.; Zhou, M. J. Am. Soc. Mass Spectrom. 2020, 31, 1783-1802.

(67) Bashir, B. A.; Giannakopulos, A. E.; Derrick, P. J.; Critchley, P.; Bottrill, A.; Padley, H. D. Eur. J. Mass Spectrom. 2004, 10, 109-120.

(68) Gao, J.; Thomas, D. A.; Sohn, C. H.; Beauchamp, J. L. J. Am. Chem. Soc. 2013, 135, 10684-10692.

(69) Spina, E.; Sturiale, L.; Romeo, D.; Impallomeni, G.; Garozzo, D.; Waidelich, D.; Glueckmann, M. Rapid Commun. Mass Spectrom. 2004, 18, 392-398. 
(70) Maslen, S. L.; Goubet, F.; Adam, A.; Dupree, P.; Stephens, E. Carbohydr. Res. 2007, 342, 724-735.

(71) De Leoz, M. L. A.; Simón-Manso, Y.; Woods, R. J.; Stein, S. E. J. Am. Soc. Mass Spectrom. 2019, 30, 426-438.

(72) Schaller-Duke, R. M.; Bogala, M. R.; Cassady, C. J. J. Am. Soc. Mass Spectrom. 2018, 29, 1021-1035.

(73) He, H.; Wen, Y.; Guo, Z.; Li, P.; Liu, Z. Anal. Chem. 2019, 91, 8390-8397.

(74) Garrozzo, D.; Impallomeni, G.; Spina, E.; Sturiale, L.; Zanetti, F. Rapid Commun. Mass Spectrom. 1995, 9, 937-941.

(75) Malvagna, P.; Impallomeni, G.; Cozzolino, R.; Spina, E.; Garozzo, D. Rapid Commun. Mass Spectrom. 2002, 16, 1599-1603. 